\title{
Ovarian Pregnancy in Association with a Copper 7 Intrauterine Contraceptive Device
}

\author{
Major B. Johnston, \\ MRCOG RAMC \\ Senior Specialist in Obstetrics and Gynaecology \\ Cambridge Military Hospital, Aldershot
}

SUMMARY: A case of ovarian ectopic pregnancy is described which satisfies all of Spiegelberg's criteria and in the discussion the reasons for the apparent association with an intrauterine contraceptive device are examined.

\section{Introduction}

Ovarian pregnancy is a rare gynaecological condition for which 4 criteria laid down by Spiegelberg in $1878^{1}$ must be satisfied in order to make the diagnosis.

a. The fallopian tube on the affected side must be normal.

b. The gestation sac must occupy the normal position of the ovary.

c. The sac must be connected to the uterus by the ovarian ligament.

d. Ovarian tissue must be histologically demonstrated in the wall of the sac.

In $1951 \mathrm{Hertig}^{2}$ estimated that ovarian pregnancy accounted for $0.7-1 \%$ of all ectopic pregnancies with an overall incidence of 1 in 25,000 to 1 in 40,000 of all pregnancies. Over the past 15 years there has been an apparent increase in the incidence of ectopic pregnancies in association with intrauterine contraceptive devices (IUCD's) and in 1978, Berger and Blechner ${ }^{3}$ showed that, in IUCD users who developed ectopic pregnancies, one ovarian pregnancy occurred for every nine tubal pregnancies.

\section{Case Report}

A 37 year old patient para $3+0$, who had a Copper 7 IUCD in situ for two years was admitted to hospital with a history of 6-8 weeks amenorrhoea followed by two weeks of intermittent vaginal bleeding and, on the morning of admission an attack of severe lower abdominal pain. On examination she was clinically shocked, in severe pain, and tender over the lower abdomen with rigidity and rebound tenderness. Vaginal examination revealed marked pelvic tenderness and clinically an ectopic pregnancy was suspected. Laparoscopy revealed the presence of blood and clot in the pelvis and a laparotomy was performed. The bleeding was coming from a lesion in the right ovary; the right fallopian tube and left ovary and tube were normal. A right salpingo-oophorectomy was performed and approximately $500 \mathrm{mls}$ of blood evacuated from the abdomen and pelvis. The IUCD was removed from the uterus at the time of laparoscopy. The patient made an uneventful recovery and was discharged home on the sixth postoperative day.
The macroscopic appearance of the right ovary is seen at Fig. 1. Histology showed that the lesion was a gestation sac enlarging the right ovary and all four of Spiegelberg's criteria were satisfied, thus confirming a diagnosis of ovarian ectopic pregnancy.

\section{Discussion}

As mentioned in the introduction, the incidence of ovarian pregnancy in 1951 was very low and representeg only $0.7-1 \%$ of all ectopic pregnancies. However, ove? the past fifteen ycars several studies reviewing th@ incidence of ovarian ectopics (particularly in IUCI users) have shown that the rate of ovarian to otheg ectopic pregnancies is much higher. Lchfeld quoted ab incidence of one ovarian pregnancy for every two hundred other ectopic pregnancies in non-IUCD users rising to one in nine in the presence of an IUCD. This was confirmed by Berger and Blechner ${ }^{3}$ who found the same incidence in a series of thirty three ectopic pregnancies in IUCD users.

This change in incidence in relation to the use of IUCD's has led some authors to postulate that IUCD's have some causal relationship with ectopic pregnancy and in particular with ovarian pregnancy. Piver ${ }^{5}$ suggested that altered tubal motility might account for the increased incidence in IUCD users and Darwish and Safaan ${ }^{6}$ postulated that alterations in prostaglandin levels might cause reversed tubal peristalsis and subsequent ovarian implantation. Other authors ${ }^{7,8,9,10}$ have put forward the idea that a higher incidence of salpingitis amongst IUCD users was in some way responsible although it has also been claimed ${ }^{11}$ that patients with an IUCD and an ectopic pregnancy of any kind had a lower incidence of pelvic inflammatory disease than nonIUCD users, due, they believe, to the fact that a history of salpingitis is a contra-indication to the fitting of an IUCD.

Lehfeld et al in $1970^{4}$ put forward the theory (based upon statistical examination of 45,000 woman years of $N$ experience of IUCD's) that an IUCD reduces the number of intrauterine implantations by $99.5 \%$, tubal implantations by $95 \%$ and ovarian implantations not at all, thus resulting in a false impression of a raised incidence of ectopic pregnancy, especially in the ovary. 


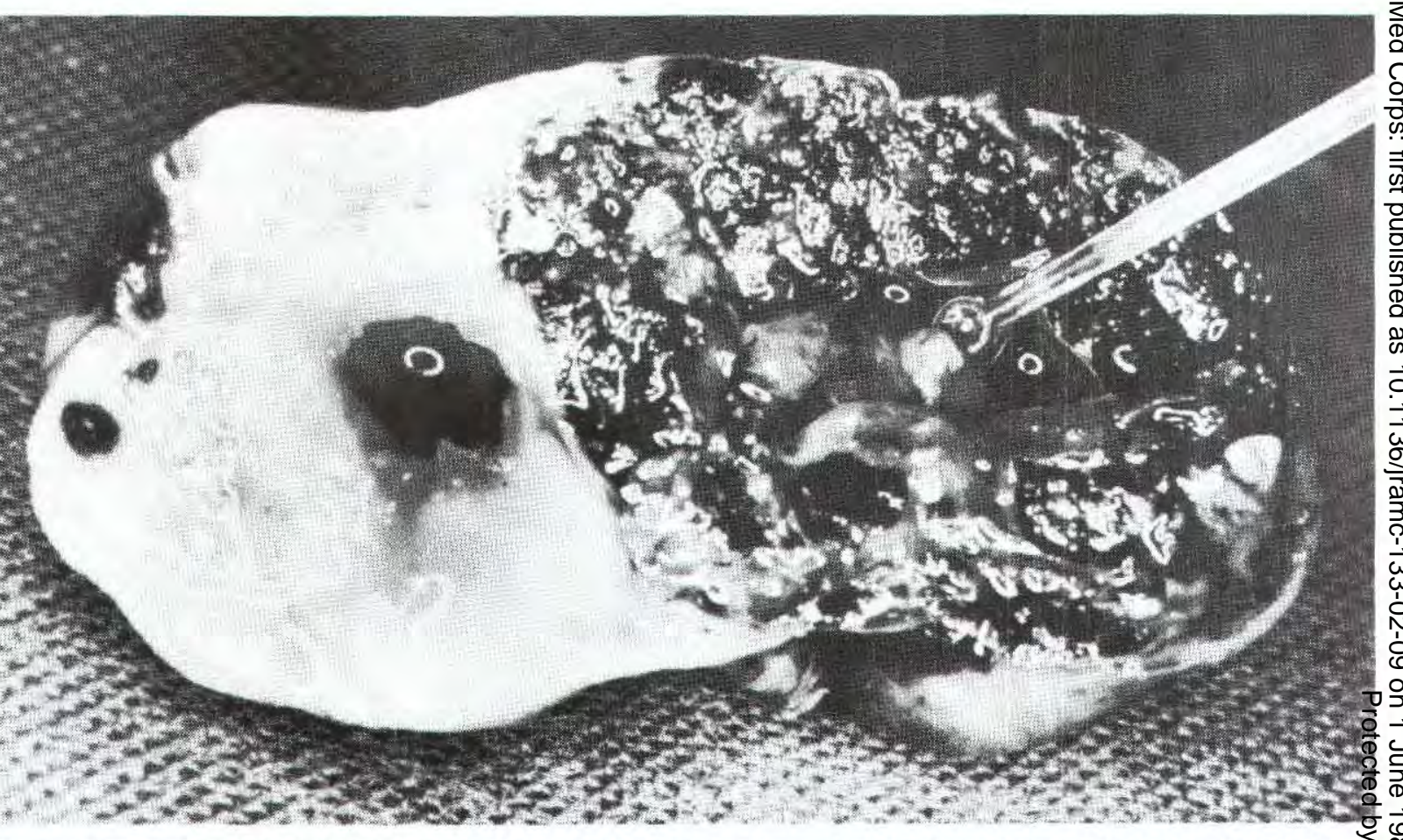

Fig. 1. A cross section of the right ovary showing the trophoblastic tissue surrounding a small gestational sac with the embryo indicate $\varnothing$. by the pointer. Normal ovarian tissue is seen to the left, the cystic area being a corpus luteum.

This theory has however been challenged by some authors $^{y .12}$ who question the validity of the statistical analysis, but there are no other data available to explain the changing frequency of ovarian implantation in the presence of IUCD's. There is no evidence to support the idea that IUCD's predispose to ovarian implantation and indeed there is no evidence to suggest that they predispose to tubal implantation cither. Lehfeld's theory that tubal and ovarian pregnancies in IUCD users reflect a failure on the part of the coil to protect the patient from this form of implantation, rather than its cause, seems to be the most credible and would account for the relatively increased frequency of ectopic pregnancy in the presence of IUCD's.

\section{Acknowledgements}

I would like to thank Mrs G Shepherd for her assistance in typing this paper.

\section{REFERENCES}

1. SPeigel berg O. Zur Casuistick der Ovarial schwengerschaft. Arch Gynaekol 1878; 13: 73.

2. Hertig A T. Discussion of Gerin Lapsie's paper. Amer J Obstet Gynecol 1951:62: 926.

3. Berger B and Blechner J N. Ovarian pregnancy associated with Copper 7 IUCD. Obstet Gynecol 1978; 52: 597 .
4. LemFeld $\mathrm{H}$, TIETZE $\mathrm{C}$ and Garstein F. Ovariain pregnancy and the IUCD. Amer J Obstel Gynecol 1970; 108: 1005 .

5. PIVER M S, BaER $\mathrm{K}$ A and Zachary T V. Ovarian pregnancy and IUCD JAMA 1967;201: 323.

6. DARWISH D H and SAFAAN S T A. Ovarian ectopic pregnancy with an IUCD. Br Med J 1975: 4: 143

7. HaLlat J G. Ectopic pregnancy associated with the IUCD: a study of seventy cases. Amer J Obstet Gynecol 1976; 125: 754

8. Kalierberger D A, Ronk D A and Jimersos G N. Ectopic pregnancy: a 15 year review of 160 cases. South Med J1978; 71: 758 .

9. Sivin I. Copper-T IUCD use and ectopic pregnancy rates Contraception 1979; 19: 151.

10. WESTERN L. Effects of acute pelvic inflammatory disease on fertility. Amer J Obstet Gynecol 1975: 121: 707.

11. ERKNOLA R and LUINKOP. Intra uterine device and ectopic pregnancy. Contraception 1977; 16:569

12. KJER J J, Holm B and Hertz J. Ovarian pregnancy in IUCD uscrs. Acta Obstet Gynecol Scand 1981; 60: $337-339$ 